\title{
Evaluasi Sistem Pencatatan Dan Pelaporan Kasus Tuberculosis Di Rumah Sakit Syarif Hidayatullah
}

\section{Tuberculosis Cases Recording and Reporting System Evaluation at Syarif Hidayatullah Hospital}

\author{
Yunita Ratnasari ${ }^{1}$, Amal Chalik Sjaaf ${ }^{2}$, Achmad Djunawan $^{3}$ \\ ${ }^{1}$ Health Policy and Administration Postgraduate Program,Universitas Indonesia \\ ${ }^{2}$ Health Policy and Administration Department Faculty, Universitas Indonesia \\ ${ }^{3}$ Hospital Administration Program of Stikes Yayasan Rumah Sakit Dr Soetomo \\ *Corresponding authors email: neechan03@gmail.com
}

\begin{abstract}
ABSTRAK
Target program penanggulangan $T B$ nasional yaitu eliminasi pada tahun 2035 dan Indonesia bebas TB tahun 2050. Rumah sakit harus menetapkan Tim DOTS yang bertanggung jawab terhadap pelaksanaan program Penanggulangan $T B$ dan wajib melakukan pencatatan dan pelaporan terhadap setiap kejadian penyakit. Pelaporan kasus TB menggunakan Sistem Informasi Tuberkulosis Terpadu (SITT) yang menjadi Sistem Informasi Tuberkulosis (SITB) sejak tahun 2020. RS Syarif Hidayatullah termasuk 1 dari 3 rumah sakit yang belum melengkapi pelaporan dalam SITB. Perlu adanya penelitian yang bertujuan untuk mengevaluasi penyebab tidak lengkapnya pelaporan kasus $T B$ di Rumah Sakit Syarif Hidayutallah. Penelitian ini mengevaluasi ketidaklengkapan laporan kasus TB menggunakan fishbone diagram dari segi input meliputi man, money, material, dan method. Penelitian ini merupakan penelitian kualitatif dengan desain studi kasus. Teknik pengambilan data dalam penelitian ini adalah dengan telaah dokumen, observasi dan wawancara mendalam pada informan kunci. Teknik sampling dalam penelitian ini adalah purposive sampling. Hasil penelitian ini menunjukkan bahwa pencatatan dan pelaporan kasus TB tidak berjalan maksimal karena 1) kurangnya SDM perawat sebagai ujung tombak pencacatan manual, 2) belum adanya pendanaan untuk program TB DOTS termasuk untuk pencatatan dan pelaporan, 3) belum terintegrasinya SIMRS ke semua unit pelayanan, 4) jejaring internal tidak berjalan baik. Upaya yang dapat dilakukan adalah peningkatan komitmen manajemen Rumah Sakit Syarif Hidayatullah dalam implementasi program TB DOTS.
\end{abstract}

Kata Kunci: Rumah Sakit, SITB, SITT, TB DOTS

\section{ABSTRACT}

The target of the national TB control program is elimination by 2035 and Indonesia free of TB by 2050. Hospitals must establish a DOTS team that is responsible for implementing the TB control program and must record and report any disease incidents. $T B$ case reporting uses the Integrated Tuberculosis Information System (SITT) which has been the Tuberculosis Information System (SITB) since 2020. Syarif Hidayatullah Hospital is one of 3 hospitals that have not completed reporting in the SITB. There is a need for research that aims to evaluate the causes of incomplete reporting of TB cases at Syarif Hidayutallah Hospital. This study evaluates the incompleteness of TB case reports in terms of inputs including man, money, material, and method. This research is a qualitative research with a case study design. The data collection technique in this study was document review, observation and in-depth interviews with key informants. The sampling technique in this study was purposive sampling. The results of this study indicate that the recording and reporting of TB cases is not running optimally because 1) the lack of human resources for nurses as the spearhead of manual mutilation, 2) there is no funding for the TB DOTS program including for recording and reporting, 3) the SIMRS has not been integrated into all service units, 4) the internal network is not working properly. Syarif Hidayutallah Hospital need to increase the management commitment in implementing the TB DOTS program.

Keywords: Hospital, SITB, SITT, TB DOTS 
Yunita Ratnasari, Amal Chalik Sjaaf, Achmad Djunawan : Evaluasi Sistem Pencatatan Dan .....

\section{PENDAHULUAN}

Tuberculosis (TB) merupakan penyakit menular yang menjadi penyebab utama kesehatan yang buruk, salah satu dari 10 penyebab kematian teratas di seluruh dunia dan penyebab utama kematian dari satu agen infeksius (peringkat di atas HIV / AIDS) (WHO, 2019). Penyebab TB adalah Mycobacterium Tuberculosis sejenis kuman berbentuk batang. Proses terjadinya infeksi oleh Mycobacterium Tuberculosis biasanya secara inhalasi sehingga $T B$ paru merupakan manifestasi klinis yang paling sering, tetapi juga dapat mempengaruhi organ lain (Burhannuddin, 2015; Mertaniasih, 2019; WHO, 2019). Secara global, diperkirakan 1,7 miliar orang terinfeksi Mycobacterium Tuberculosis dan mempunyai risiko menyebarkan penyakit (WHO, 2019).

Target SDG's untuk TB di tahun 2030 adalah penurunan 90\% dalam jumlah kematian akibat TB dan 80\% penurunan tingkat kejadian TB (kasus baru per 100.000 penduduk per tahun) dibandingkan dengan tahun 2015 (WHO, 2019). Hal ini sejalan dengan Peraturan Menteri Kesehatan Nomor 67 Tahun 2016 Tentang Penanggulangan Tuberculosis yang menyatakan target program Penanggulangan TB nasional yaitu eliminasi pada tahun 2035 dan Indonesia bebas TB tahun 2050. Sejak tahun 2005 Indonesia telah menerapkan Strategi Directly Observed Treatment Short-course (DOTS) untuk penalataksaan pasien $T B$. Penatalaksanaan $T B$ di sebagian besar rumah sakit dan praktik swasta umumnya belum sesuai dengan strategi DOTS dan penerapan standar pelayanan berdasar International Standards for Tuberculosis Care (ISTC) (Kementrian Kesehatan, 2013). Berdasarkan laporan nasional Riset Kesehatan Dasar (RISKESDAS) tahun 2018 dapat diketahui bahwa jumlah prevalensi tertimbang kasus TB di Indonesia adalah 1.017.290. Provinsi Banten yang memiliki jumlah prevalensi tertimbang di sebesar 48.621.

Rumah sakit harus menetapkan Tim DOTS yang bertanggung jawab terhadap pelaksanaan program Penanggulangan $T B$ dan wajib melakukan pencatatan dan pelaporan terhadap setiap kejadian penyakit TB (Peraturan Menteri Kesehatan No. 67 Tahun 2016 Tentang Penanggulangan Tuberculosis). Pelaporan kasus TB menggunakan Sistem Informasi Tuberkulosis Terpadu (SITT). Sejak tahun 2020 SITT menjadi Sistem Informasi Tuberkulosis (SITB). Berdasarkan laporan dari SITT per bulan Maret Tahun 2020, estimasi kasus $T B$ 845.000. Kasus $T B$ ternotifikasi 543.874. Ada $35 \%$ kasus $T B$ yang tidak terlaporkan (Kemenkes RI, 2020).

Unsur pokok dalam adminitrasi kesehatan meliputi masukan (input), proses (process), keluaran (ouput), sasaran (target) serta dampak (impact). Sedangkan 
komponen input sendiri ada yang membagi menjadi 4M yaitu manusia (man), uang (money), sarana (material) dan metode (method) (Adyaningrum et al., 2019; Ariga, 2020; Rahman, 2017; Virdasari et al., 2018). Dalam pencatatan TB/HIV subsistem menggunakan 3 komponen yaitu SIMRS, SITT dan SIHA. Pencatatan yang dilakukan meliputi pencatatan pada rekam medis pasien, mencatat data pasien di buku laporan harian, pelayanan medis dan untuk laporan harian pasien umum atau catatan kunjungan pasien (Setiyadi et al., 2015).

Rumah Sakit Syarif Hidayatullah merupakan fasilitas layanan kesehatan yang sudah melakukan $M o U$ dengan Dinas Kesehatan Tangerang Selatan untuk melaksanakan program TB DOTS dan melaporkan melalui SITT dan SITB. Pada bulan Juli 2020, Dinas Kesehatan Tangerang Selatan memberikan feedback tentang pelaporan SITB rumah sakit di Tangerang Selatan. RS Syarif Hidayatullah termasuk 1 dari 3 rumah sakit yang belum melengkapi pelaporan dalam SITB. Laporan kasus TB pada triwulan 2 tahun 2020 yang tercatat dalam SITB adalah sebagai berikut total suspek 95 kasus, yang melakukan pemeriksaan laboratorium 16 kasus, TB klinis 30 kasus, TB terkonfirmasi bakteriologis 2 kasus dan pasien yang memulai pengobatan 14 kasus, sedangkan laporan kesembuhan atau pengobatan lengkap belum terlaporkan. Berdasarkan informasi tersebut dapat diketahui bahwa belum semua kasus dilaporkan secara lengkap baik dari segi pemeriksaan laboratorium maupun evaluasi hasil pengobatan. Berdasarkan hal tersebut peneliti bermaksud menganalisis bagaimanakah pencatatan dan pelaporan kasus TB di RS Syarif Hidayatullah dari komponen input.

\section{METODE}

Penelitian ini merupakan penelitian kualitatif dengan desain penelitian studi kasus. Penelitian ini menggunakan fishbone diagram untuk mengidentifikasi kemungkinan penyebab masalah dari segi input meliputi man, money, material, dan method. Penelitian dilakukan di RS Syarif Hidayatullah, Ciputat, Tangerang Selatan pada bulan November 2020. Teknik pengambilan data dengan telaah dokumen, observasi dan wawancara mendalam pada informan kunci. Teknik pengambilan sampel dalam penelitian ini adalah pusposive sampling. Informan kunci pada penelitian ini adalah petugas penanggungjawab jejaring internal dalam pelaporan SITT dan STIB sebanyak 5 orang, serta 1 orang manajer medis di RS Syarif Hidayatullah. Kriteria inklusi dalam pemilihan informan adalah pihak bertanggung jawab atas pencatatan dan polaporan TB. Kriteria ekslusi dalam penelitian ini adalah petugas yang tidak bersedia menjadi informan. Validitas data pada 
Yunita Ratnasari, Amal Chalik Sjaaf, Achmad Djunawan : Evaluasi Sistem Pencatatan Dan .....

penelitian ini dipastikan menggunakan triangulasi sumber dan triangulasi metode.

\section{HASIL}

Hasil penelitian ini dibagi menjadi komponen man, money, material dan methode. Berdasarkan hasil telaah dokumen, terdapat 4 petugas yang sudah memiliki sertifikat TB DOTS. Petugas tersebut bertanggung jawab terhadap pelaporan dalam SITT dan SITB. Data pelaporan diambil dari pencatatan manual di tiap unit pelayanan dan dari SIMRS. Pasien TB di unit rawat jalan tidak hanya terpusat di poli paru namun tersebar di beberapa poli lain seperti bedah, saraf, penyakit dalam, anak, THT. Banyaknya poli perawatan pasien TB mengakibatkan rumah sakit mengandalkan perawat yang menjadi asisten di tiap poli untuk melakukan pencatatan. Saat ini satu perawat bisa menjadi asisten di 2 sampai 3 poli, Terkadang tidak semua pasien dapat tercatat di buku pelaporan. Hal ini dikarenakan saat dokter memeriksa pasien, perawat sedang mendampingi dokter lain di poli lain.

"SDM perawat di rawat jalan sedikit, tidak semua dokter sepenuhnya didampingi oleh perawat, jadi tidak semua pasien bisa tercatat". Petugas jejaring internal rawat jalan-

Berdasarakan hasil wawancara juga diketahui bahwa sosialisasi program TB baru dilakukan satu kali dan belum semua petugas mengikuti sosialisasi tersebut. Sosialisasi diselenggarakan oleh pihak manajemen. Pemateri atau narasumber sosialisasi adalah dokter spesialis paru. Belum semua petugas mendapat sosialisasi tentang pencatatan pasien TB sehingga mereka tidak proaktif melakukan pencatatan. Selain itu, tidak semua dokter mendapat sosialisasi mengenai program TB di rumah sakit sehingga tidak ada intruksi kepada perawat asisten untuk melakukan pencatatan pasien TB. Berdasarkan data unit diklat dapat diketahui bahwa kurang lebih 30\% dokter tidak dapat mengikuti sosialisasi tersebut. Ketidakhadiran dokter tersebut disebabkan karena adanya kesibukan dokter di tempat lain saat sosialisasi diselengarakan. Kejadian ini disebabkan karena status dokter tersebut adalah dokter mitra atau bukan dokter tetap RS Syarif Hidayatullah.

Semua sumber pendanaan program TB DOTS berasal dari anggaran tahunan, yang tercantum dalam program kerja. Berdasarkan hasil telaah dokumen program kerja $T B$ DOTS diketahui bahwa program kerja TB DOTS tahun 2020 belum ada. Program kerja tahunan rumah sakit saat ini belum memuat dana khusus untuk program TB DOTS ini. Insentif khusus untuk petugas pelaporan tentunya juga belum ada. Hal ini disebabkan tidak adanya surat keputusan tentang pengangkatan petugas TB DOTS termasuk petugas 
pencatatan dan pelaporan. Tidak adanya program TB DOTS juga menyebabkan tidak adanya anggaran untuk TB DOTS.

Sarana dan prasarana yang dibutuhkan dalam pencatatan dan pelaporan antara lain buku pencatatan manual, buku registrasi kunjungan pasien harian, rekam medis pasien, dan data kunjungan dari SIMRS. Berdasarkan hasil observasi didapatkan buku pencatatan manual pasien $T B$ sudah tersedia di unit rawat jalan, rawat inap dan laboratorium, sedangkan di UGD belum ada buku pencatatan manual pasien TB. Form baku untuk pencatatan $T B$ yang sudah tersedia antara lain form TB 01, form TB 02, buku TB 03, buku TВ 04, form ТВ 05 dan buku ТВ 06. Buku pencatatan manual tersebut berguna untuk mengisi pelaporan dalam SITT maupun SITB. Pencatatan pasien TB dalam buku laporan manual dilakukan oleh perawat di tiap unit dan untuk laboratorium dilakukan oleh analis.

Petugas pelaporan juga menarik data pasien TB dari SIMRS untuk melengkapi data dari pencatatan dalam formulir manual. Namun Sistem Informasi Rumah Sakit belum terintegrasi di semua unit sehingga petugas pelaporan kesulitan menemukan semua pasien terduga $T B$ maupun pasien $T B$. Selain itu, hanya petugas bagian IT yang dapat menarik data dari SIMRS. Hal ini berguna untuk melacak pasien yang tidak kembali mengambil obat, itupun harus mencari di tiap unit pelayanan untuk bisa mendapatkan daftar pasien terduga $T B$ maupun pasien $T B$.

"SIMRS tidak terinegrasi ke semua unit, jadi kalau kita ingin menarik data harus ke petugas IT. Itu juga tidak bisa langsung ada datanya." petugas jejaring internal rawat inap-

Kendala lain yang berhubungan dengan SIMRS adalah sistem tersebut tetap bisa menyimpan data pasien walaupun petugas tidak memasukkan nomor identitas pasien. Nomor identitas pasien sangat diperlukan dalam pelaporan TB agar dapat melacak pasien yang tidak kembali untuk berobat. Nomor identitas juga digunakan untuk mengetahui kepindahan pasien ke fasilitas pelayanan kesehatan lain tanpa pemberitahuan.

"petugas pendaftaran sering tidak mengisi nomor KTP jadi kelengkapan data pasien TB tidak sesuai yang diminta dalam SITT maupun SITB. Padahal sekarang di SITB, kalau pasien pindah tanpa pemberitahuan kita bisa tahu dengan melihat nomor KTP” - Petugas pelaporan-

Dokumen regulasi yang mengatur jejaring internal maupun eksternal pelaporan TB sudah ada berupa Standar Prosedur Operasional (SPO). Namun pelaksanannya belum maksimal, hal ini disebabkan belum adanya sosialisasi regulasi tersebut kepada semua unit pelayanan. 
Yunita Ratnasari, Amal Chalik Sjaaf, Achmad Djunawan : Evaluasi Sistem Pencatatan Dan .....

“... belum ada sosialisasi ke UGD mengenai pelaporan TB ini. Kalau disuruh rekap pasien TB ya pasti akan kami lakukan.”-Petugas jejaring internal IGD-

Penanggung jawab jejaring internal tiap unit untuk melakukan pencatatan pada buku laporan manual. Selanjutnya laporan tersebut akan dimasukkan ke dalam SITT dan SITB oleh petugas pelaporan. Rawat inap pencatatan di rawat inap dilakukan oleh kepala ruang setelah mendapatkan laporan dari perawat yang sedang berjaga saat itu.

Alur pelaporan khusus untuk pasien $T B$ di rawat jalan sendiri belum diatur dalam regulasi rumah sakit sehingga penanggung jawab jejaring internal rawat jalan kesulitan dalam melacak pasien TB. Perawat yang menjadi asisten di tiap poli juga tidak melaporkan temuan pasien $T B$ kepada penanggung jawab pencatatan di rawat jalan.

\section{PEMBAHASAN}

Pada poin man, sosialisasi program $T B$ yang baru dilakukan satu kali dan tidak semua petugas mengikuti sosialisasi tersebut merupakan hambatan dalam pencatatan dan pelaporan kasus TB. Hambatan ini sejalan dengan penelitian yang dilakukan Tondong dkk tahun 2014 bahwa keterbatasan sumber daya manusia baik jumlah maupun jenisnya dan beban kerja tinggi menjadi hambatan berjalannya program $T B$ di fasilitas pelayanan kesehatan. Bantuan dari manajer kasus perawat $T B$ dapat meningkatkan tingkat pelaporan yang kurang baik (Morales García et al., 2015). Kecukupan sumber daya manusia dalam pelaporan kasus TB tidak hanya sebatas pada kuantitas tetapi juga kualitas. Pernyataan ini didukung oleh hasil penelitian Erdini, Dwimawati, dan Chotimah yang menunjukkan bahwa meskipun sumber daya manusia cukup tetapi tidak semua mendapatkan pelatihan. Sumber daya manusia yang tidak mendapatkan pelatihan maka pelaporan kasus TB tidak dapat berjalan maksimal (Erdini et al., 2020). Berdasarkan hasil diatas dapat diketahui bahwa Rumah Sakit Syarif Hidayatullah belum memenuhi unsur kuantitas dan kualitas. Peningkatan kuantitas dan kualitas ini penting dilakukan agar pelaporan TB dapat berjalan dengan baik.

Money atau uang merupakan unsur penting dalam pelaksanaan suatu program. Program Pengendalian TB penting agar mendorong pelaporan kasus secara menyeluruh untuk meningkatkan pengendalian penyakit (Morales García et al., 2015). Uang ini dapat dibelanjakan untuk keperluan sarana dan prasarana. Uang ini juga penting untuk memberikan reward kepada pelaksana dan penanggung jawab pelaporan kasus $T B$. Imbalan kepada petugas $T B$ diperlukan selain untuk meningkatkan motivasi, juga untuk 
memperlancar program (Minardo, 2014). Penilaian komitmen dan organisasi tim DOTS RS menurut daftar tilik Subdit TB Kemenkes salah satunya yaitu RS menyediakan dana operasional tim DOTS RS (Reviono et al., 2019). Berdasarkan hasil bahwa belum ada anggaran khusus untuk tim DOTS di Rumah Sakit Syarif Hidayatullah. Rumah sakit ini merupakan rumah sakit swasta yang tidak mendapatkan anggaran dari pemerintah. Pihak manajemen rumah sakit perlu untuk menganggarkan biaya kegiatan tim DOTS ini agar pelaporan dapat berjalan dengan baik.

Pada poin material ini, pelaksanaan pencatatan dan pelaporan di RS cukup baik. Sistem yang belum terintegrasi berdampak pada terjadinya redundancy dan duplikasi data (Setiyadi et al., 2015). Integrasi data penting dalam informasi kesehatan, dengan terintegrasinya seluruh data di suatu sistem, maka akan sangat mudah dalam melakukan input data, menyusun pelaporan dan selain itu juga memudahkan dalam proses pengambilan keputusan. Integrasi data tidak akan terlepas dengan peralatan dan system elektronik. Sistem elektronik ini harus dipenuhi agar pelaporan kasus TB dapat berjalan maksimal (Fahmi, 2016).

Pencatatan pasien TB dalam buku laporan manual dilakukan oleh perawat di tiap unit dan laboratorium dilakukan oleh analis. Sesuai dengan Peraturan Menteri Kesehatan No. 67 Tahun 2016 Tentang Penanggulangan Tuberculosis bahwa data diperoleh dari sistem pencatatan-pelaporan. Pencatatan menggunakan formulir baku secara manual didukung dengan sistem informasi secara elektronik, sedangkan pelaporan TB menggunakan sistem informasi elektronik. Di Semarang, sejak tahun 2019 fasilitas kesehatan seperti puskesmas, rumah sakit, balkesmas, klinik, LP, DOTS telah menggunakan aplikasi digital untuk pelaporan kasus TB (Setyowati \& Prasetya, 2020). Di Jember terdapat program wajib notifikasi melalui aplikasi berbasis android untuk pelaporan kasus TB (Wadudah et al., 2020). Berdasarkan penelitian tersebut dapat diketahui bahwa aspek ketersediaan fasilitas elektronik digital menjadi sangat penting dalam pelaporan kasus TB.

SIMRS harusnya tidak bisa menyimpan data pasien ketika petugas tidak memasukkan nomor identitas pasien. Nomor identitas pasien sangat diperlukan dalam pelaporan TB agar dapat melacak pasien yang tidak kembali untuk berobat. Nomor identitas juga digunakan untuk mengetahui kepindahan pasien ke fasilitas pelayanan kesehatan lain tanpa pemberitahuan. Pada April 2012- februari 2015 terdapat 47 dari 384 pasien TB yang tidak berobat di RSUP Dr. Hasan Sadikin Bandung (Suryanto et al., 2017). Nomor identitas merupakan komponen penting dalam pelacakan pasien TB untuk 
Yunita Ratnasari, Amal Chalik Sjaaf, Achmad Djunawan : Evaluasi Sistem Pencatatan Dan .....

keberlanjutan pengobatan.

Pada poin method ini terdapat sistem pelaporan TB yang baru yaitu SITB. Petugas penanggung jawab pelaporan hasil laboratorium dapat melakukan input data mandiri. Petugas yang sudah terlatih dan bersertifikat hanya satu orang analis. Petugas ini melakukan pelaporan berdasar dari buku laporan manual yang sudah diisi oleh analis yang melakukan pemeriksaan BTA. Analis yang berjaga juga sudah mendapatkan sosialisasi mengenai pelaporan pemeriksaan BTA untuk pasien TB. Namun pada pelaksanaannya petugas belum lengkap mengisi buku pencatatan manual.

Tidak lengkapnya pengisian menyebabkan petugas pelaporan menarik data pasien $T B$ dari SIMRS untuk melengkapi data dari pencatatan dalam formulir manual. Kendala lain yaitu sistem informasi rumah sakit belum terintegrasi di semua unit sehingga petugas pelaporan kesulitan menemukan semua pasien terduga TB maupun pasien TB. Harusnya formulir dilengkapi agar tidak perlu akses sistem informasi rumah sakit untuk menarik data pasien atau terduga pasien TB. Pengisian manual (offline) yang berjalan baik belum tentu pelaporan SITT (online) juga berjalan baik (Faizah \& Raharjo, 2019). Berdasarkan penelitian tersebut bahwa pencatatan manual merupakan hal penting sebelum melakukan pelaporan online.

Berdasarkan hasil penelitian sebelumnya disebutkan bahwa jejaring internal yang tidak berfungsi dengan baik disebabkan karena kurangnya komitmen manajemen rumah sakit, tim DOTS yang memiliki beban tugas rangkap, dan kurangnya komunikasi antar unit jejaring internal (Tondong et al., 2014). Komitmen dan organisasi tim DOTS menjadi salah satu penilaian menurut Subdit TB kemenkes. Komitmen organisasi dan kebijakan diperlukan untuk memperkuat program TB DOTS di rumah sakit. Agar implementasi suatu kebijakan berhasil, diperlukan dasar hukum yang jelas. Dasar hukum yang jelas ini bertujuan agar para petugas patuh. Dasar hukum ini tentunya memerlukan dukungan dari stakeholder (Reviono et al., 2019). Jejaring internal ini merupakan method, tetapi penyebab tidak berjalannya jejaring internal di Rumah Sakit Syarif Hidayatullah adalah faktor man, money, dan material. Upaya perbaikan tersebut dapat dilihat dari komitmen pihak manajemen rumah sakit dalam menyelesaikan faktor penyebab tidak berjalanya jejaring internal, lebih luas lagi pada pelaporan $T B$.

\section{SIMPULAN}

Pencatatan manual di rawat jalan tidak berjalan maksimal, dikarenakan pasien $T B$ belum terpusat pada satu poli TB DOTS serta kurangnya tenaga perawat sebagai ujung 
tombak pencatatan dalam formulir TB. Komitmen manajemen dalam pelaksanaan program TB DOTS termasuk pelaporan dan pencatatan belum maksimal terlihat dari belum adanya dana untuk program $T B$ sendiri. SIMRS belum terintegrasi ke semua unit yang mengakibatkan kesulitan dalam penarikan data pasien TB. Upaya yang dapat dilakukan adalah peningkatan komitmen manajemen Rumah Sakit Syarif Hidayatullah dalam implementasi program TB DOTS.

\section{UCAPAN TERIMA KASIH}

Ucapan terima kasih kepada staff dan pihak manajemen Rumah Sakit Syarif Hidayatullah, Ciputat, Tangerang Selatan karena telah memberikan ijin dan membantu demi kelancaran penelitian ini.

\section{DAFTAR PUSTAKA}

Adyaningrum, N., Suryawati, C., \& Budiyanti, R. T. (2019). Analisis Pengawasan Menelan Obat Pasien Tuberkulosis (TB) dalam Program Penanggulangan TB di Puskesmas Sempor II Kabupaten Kebumen. Jurnal Kesehatan Masyarakat (Undip), 7(4), 542-555.

Ariga, R. A. (2020). Buku Ajar Implementasi Manajemen Pelayanan Kesehatan Dalam Keperawatan. Deepublish.

Burhannuddin. (2015). Imunologi, Infeksi Laten Dan Mekanisme Reaktivasi Mycobacterium tuberculosis. Jurnal Meditory, 3(2).

Erdini, D., Dwimawati, E., \& Chotimah, I. (2020). Evaluasi Program TB Paru di Puskesmas Ciampea Kabupaten Bogor Tahun 2019. Jurnal Mahasiswa Kesehatan Masyarakat, 3(5).

Fahmi, N. (2016). Pemanfaatan dan penggunaan sistem elektronik tuberkulosis di dinas kesehatan provinsi kalimantan selatan. Journal of Information Systems for Public Health, 1(3), 1-7.

Faizah, I. L., \& Raharjo, B. B. (2019). Penanggulangan Tuberkulosis Paru dengan Strategi DOTS ( Directly Observed Treatment Short course ). Higeia Journal of Public Health Research and Development, 3(3), 430-441. https://journal.unnes.ac.id/sju/index.php/higeia/article/view/25499

Peraturan Menteri Kesehatan No. 67 Tahun 2016 tentang Penanggulangan Tuberculosis.

Kemenkes RI. (2020). Situasi TB di Indonesia. https://tbindonesia.or.id/pustakatbc/dashboard-tb/

Kementrian Kesehatan. (2013). Buku Pegangan Sosialisasi Jaminan Kesehatan Nasional dalam Sistem Jaminan Sosial Nasional. In Departemen Kesehatan RI.

Mertaniasih, N. M. (2019). Buku Ajar Tuberkulosis Diagnostik Mikrobiologis. Airlangga University Press.

Minardo, J. (2014). Analisis Determinan Motivasi Petugas Tuberkulosis Paru dalam Penemuan Kasus di Kabupaten Semarang (Studi Kasus di Beberapa Puskesmas) Tahun 2012. PROSIDING SEMINAR NASIONAL \& INTERNASIONAL, 2(1).

Morales García, C., Rodrigo, T., García Clemente, M. M., Muñoz, A., Bermúdez, P., Casas, F., Somoza, M., Milá, C., Penas, A., \& Hidalgo, C. (2015). Factors associated with unreported tuberculosis cases in Spanish hospitals. BMC Infectious Diseases, 15(1), 1-8.

Rahman, M. (2017). Ilmu administrasi (Vol. 1). Sah Media. 
Reviono, R., Ramadhiana, Y., Probandari, A. N., \& Setianingsih, W. (2019). Factors Associated with Success Rate for Tuberculosis Treatment in Hospital: A Directly Observed Treatment Short Tuberculosis Prevention Strategy in Central Java. Journal of Epidemiology and Public Health, 4(4), 283-295.

Setiyadi, N. A., Arozaq, M., Hakam, F., Murti, B., \& Sulaeman, E. S. (2015). Analisis Sistem Pencatatan dan Pelaporan Online TB/HIV di BBKPM Surakarta. PROSIDING SEMINAR NASIONAL \& INTERNASIONAL.

Setyowati, M., \& Prasetya, J. (2020). Penilaian Pencatatan dan Pelaporan Tuberkulosis Berbasis Semar Betul (Semarang Berantas Tuberkulosis) dengan Metode Pieces di Puskesmas Kota Semarang. Jurnal Kesehatan, 13(2), 106-118.

Suryanto, D., Saraningsih, I., Andriyoko, B., \& Santoso, P. (2017). Pelacakan Pasien TB MDR Terkonfirmasi Yang Belum Memulai Pengobatan Di RSUP Dr . Hasan Sadikin Bandung Periode April 2012- Februari 2015. Indonesian Journal Chest \& Critical Care Medicine, 4(1).

Tondong, M. A. P., Mahendradhata, Y., \& Andono Ahmad, R. (2014). Evaluasi implementasi public private mix pengendalian tuberkulosis di kabupaten Ende Provinsi Nusa Tenggara Timur tahun 2012. Jurnal Kebijakan Kesehatan Indonesia, 3(1).

Virdasari, E., Arso, S. P., \& Fatmasari, E. Y. (2018). Analisis Kegiatan Pendataan Keluarga Program Indonesia Sehat Dengan Pendekatan Keluarga di Puskesmas Kota Semarang (Studi Kasus pada Puskesmas Mijen). Jurnal Kesehatan Masyarakat (e-Journal), 6(5), 52-64.

Wadudah, F., Prasetyowati, I., \& Bumi, C. (2020). Pelaksanaan Wajib Notifikasi (WiFi) TB di Dinas Kesehatan Kabupaten Jember. E-Journal Pustaka Kesehatan, 8(2), 131-138.

WHO. (2019). Global Tuberculosis Report.

\begin{tabular}{|l|l|}
\hline Submission & 16 Februari 2021 \\
\hline Review & 27 Februari -26 Maret 2021 \\
\hline Accepted & 27 Maret 2021 \\
\hline Publish & 12 April 2021 \\
\hline DOI & $10.29241 /$ jmk.v\%vi\%i.607 \\
\hline Sinta Level & Tiga (3) Nasional Akreditasi \\
\hline
\end{tabular}

